\title{
REVISÃO DOS MÉTODOS DE DESIGN INDUSTRIAL NO FINAL DO SÉCULO XX E O CONTEXTO SÓCIOECONÔMICO BRASILEIRO
}

\author{
Gilberto Rangel de Oliveira, Dr \\ Pontifícia Universidade Católica do Rio de Janeiro (PUC-Rio) \\ grangeldesign@gmail.com \\ Cláudia Mont'Alvão, Dra \\ Pontifícia Universidade Católica do Rio de Janeiro (PUC-Rio) \\ cmontalvao@puc-rio.br
}

Resumo: Entende-se que os estudos das metodologias de projeto são fundamentais para o desenvolvimento do Design com nível aceitável de qualidade. Estes estudos iniciaram-se na década de sessenta e vem se adaptando às demandas ao longo do tempo, considerando os aspectos sócioeconômicos principalmente do local onde são elaborados. Neste artigo, faz-se uma breve revisão das origens dos métodos em Design, apresenta-se um quadro comparativo e considerações sobre três importantes metodologias do Design do final do século XX, apontando-se o cenário onde cada metodologia foi desenvolvida. Traça-se reflexões sobre as metodologias e o cenário da época de sua chegada ao Brasil apontandose algumas críticas.

Palavras-chave: método, metodologia projetual, projeto, sócioeconômico.

\begin{abstract}
It is understood that the design method of study is fundamental for the development of design with an acceptable level of quality. The study methods in design started in the sixties and has been adapting to the demands over time, considering the socio economic aspects mainly of where they are produced. In this paper, a brief review of the origins of the methods in design and presents a comparative framework and considerations about three important methods of Design of the late twentieth century, pointing out the scenario where each methodology was developed. It is made further reflections on the methodologies and setting the time of his arrival in Brazil pointing to some criticism.
\end{abstract}

Keywords: method, methodology, project, prejectual methodology, socioeconomic. 


\section{INTRODUÇÃO}

A atividade projetual em Design requer uma ação criativa, conhecimento, acúmulo de informação e alguma experiência. Enfrenta desafios complexos como definir com precisão as atividades dos usuários e prever suas consequências sociais e psicológicas. Sabe-se que o ato de projetar em si demanda do uso de métodos de projeto, sendo que para o Design, o uso destes fundamenta a própria existência da atividade. Neste artigo será abordado as origens dos métodos de projeto de Design e serão traçadas considerações sobre três modelos metodológicos difundidos no Brasil, nas últimas décadas do século XX, fazendo-se uma relação destas ferramentas com o contexto sócioeconômico brasileiro.

Para introduzir o assunto faz-se necessário apontar a distinção entre método e metodologia de projeto ${ }^{1}$ no campo do Design. Roozenburg \& Eekels (1995), no seu livro Product Design: Fundamentals and Methods (Design de Produto Fundamentos e Métodos) apresentam uma explicação clara e direta sobre o assunto: "Metodologia de projeto é a ciência dos métodos que são ou que podem ser aplicados no projeto". Os autores evidenciam os dois significados que podem ser abordados no estudo sobre metodologia, na língua inglesa (assim como na língua portuguesa) da palavra "metodologia".

O primeiro significado é: a ciência ou o estudo do método, ou seja, a descrição, explicação e avaliação de métodos. O segundo significado de "metodologia" é: um corpo de métodos, procedimentos, conceitos e regras de trabalho empregadas por uma ciência particular, a arte ou disciplina. Nos círculos acadêmicos, o termo "metodologia" normalmente tem o primeiro significado, ou seja, um campo de estudo e pesquisa. (ROOZENBURG \& EEKELS,1995 p. 29)

Coelho (2008) lembra que em alguns casos o uso da palavra metodologia no meio acadêmico costuma ter diferentes denominações, com ênfase ao "campo teórico de determinada área ou concentrando-se em grandes áreas, como é o caso de disciplinas que trabalham conteúdos a partir das ciências biológicas, sociais, humanas ou físicas". Os estudos realizados nessas pesquisas costumam contemplar tanto a teoria metodológica em si, ou quanto sua aplicação em objetos específicos (metodologia aplicada).

É o caso, por exemplo, do curso de Design, em que o chamado método projetual é ensinado. Justifica-se esse tipo de tratamento da disciplina sobre métodos no ensino do design em FUNÇÃO de peculiaridades da profissão, que exige conhecimentos sólidos de PROJETO. (COELHO 2008, p. 255)

1 Parte deste texto foi publicado e apresentado no 9o ENEAC - Encontro Nacional de Ergonomia do Ambiente Construído, 2014 - Rio de Janeiro, sob o título: Método e metodologia projetual: o que dizem os profissionais de design de interiores e arquitetos sobre o processo. 
Neste caso, o estudo de disciplinas com esse entendimento privilegiam a chamada metodologia científica "embora trabalhem, por vezes, com procedimentos metodológicos particulares a um campo delimitado".

\section{MÉTODOS DE PROJETO EM DESIGN - A PRIMEIRA GERAÇÃO DE METODÓLOGOS}

Do ponto de vista histórico, a adoção de métodos científicos na área do Design remonta aproximadamente à década de 1950, quando a atividade rompeu alguns vínculos importantes que mantinha ainda com a tradição artística na produção de artefatos:

Christopher Jones, professor de Design na Universidade de Manchester e da Open University da Inglaterra, foi um dos pioneiros na utilização e análise de métodos aplicados ao Design. Em sua publicação Design Methods - Seeds of human futures, Jones apresenta amplo estudo sobre o desenvolvimento de suas tarefas. O autor identifica seis modelos mais conhecidos, considerando seus graus de planejamento e modelos de investigação: estratégica linear, estratégica cíclica, estratégia de ramificação, estratégia adaptativa, estratégia exploratória e estratégia fortuita ou aleatória. (CIPINIUK \& PORTINARI in COELHO (org.) 2006, p. 29)

A primeira Conference on Design Methods² (Conferência sobre Métodos em Design), ocorreu em Londres, 1962 - este evento é considerado um marco no estudo de metodologia de projeto em Design. Cross (2006) explica que a partir desse momento, método de pesquisa em Design passou a ser uma disciplina ou campo de pesquisa e destaca os primeiros autores metodólogos em Design que começaram a compor o cenário de publicações sobre o assunto como, Asimow (1962), Archer (1965) e Jones (1970).

Nesse período Christopher Alexander (1964) escreve sua famosa obra Notes on the Synthesis of Form (Anotações sobre a síntese da forma), onde propunha um método para estruturar problemas de projeto que permitiria aos projetistas ver uma representação gráfica da estrutura dos problemas não visuais (Lawson, 2011 p. 36). Christopher Alexander é considerado a melhor expressão dessa primeira geração do pensamento sobre o processo de projeto (Design Process)3. "O método de Alexander consistia em listar todas as exigências de um problema específico de um projeto e depois procurar interações entre elas". As exigências especificadas por Alexander poderiam ser critérios para a escolha de um determinado material para um projeto especifico que poderiam ser: simplicidade, desempenho, junções e economia. "Em seguida, as interações entre cada par de exigências são rotuladas como positivas, negativas ou neutras, caso se complementem, se inibam ou não tenham as interações, exceto junções/simplicidades, são negativas, já que envolvem exigências conflitantes" (LAWSON, 2011 p. 79 e 80).

2 Alguns autores traduzem Design Methods ou Design Process como "Método em projeto" ou "Processo do Projeto". Aqui preferiu-se o termo Métodos em Design e Processo em Design. Em algumas situações a palavra design será traduzida como "projeto", conforme o caso (N. do Autor)

3 Importante apontar que o texto em sua língua original (inglês), trata de "design process", termo mais amplo. No Brasil, no livro do Lawson (2011) a expressão foi traduzido com "processo de projeto". 
Observa-se que a primeira geração de metodólogos do projeto discutida a natureza do Design como uma ciência antes de prosseguir com suas descrições pessoais de técnicas o qual esperava-se que os designers seriam tentados a adotar na prática. Broadbent (1984), aponta no seu texto The Development of Design Methods (O desenvolvimento do Método em Design) do livro Developments in Design Methodology (Desenvolvimento da Metodologia do Design), organizado por Cross que, quase sem exceção, os pioneiros metodólogos levaram uma visão cartesiana de concepção: quebrando os problemas em fragmentos e resolvendo cada um deles separadamente antes de tentar alguma grande síntese.

Com o desenvolvimento das pesquisas e reflexões sobre os métodos em design, foi possível compreender que havia mais elementos no processo de projeto e sua natureza seria mais complexa. Lawson (1972) e Broadbent (1973), entre outros, continuaram suas investigações, o que acrescentou para o desenvolvimento do campo. Darke (1984) cita o trabalho de Wehrli (1968) que identificou uma série de problemas-tipo, a partir do quebra-cabeça, com uma única solução, para o problema duplamente aberto, onde o número de potenciais soluções é infinito e múltiplas soluções são procuradas. "Diferentes métodos são apropriados em diferentes níveis de complexidade. Os indivíduos podem diferir em sua abordagem ao Design". A autora também aponta para novas abordagens nas pesquisas em Design, na década de setenta que se iniciava, em especial a contribuição de Lawson (1972) que identificou dois estilos contrastantes de operação o foco no problema e da solução focada (DARKE 1884, p. 179).

Observa-se claramente a mudança de direção na abordagem das pesquisas e no entendimento da relação projeto (design) - problema. Antes, o entendimento do problema era analítico, ou seja, dividia-se o problema em partes para uma análise em separado, de forma quase que matemática. Depois da primeira geração de metodólogos o entendimento do problema passa a ser mais aprofundado e ao mesmo tempo mais abrangente. Desta forma o designer deveria conhecer as questões do projeto com mais profundidade - entender a estrutura do problema, para depois pensar em possíveis soluções.

Os métodos de Design voltados para Engenharia desenvolveram-se com muita intensidade na década de 1980, um bom exemplo é a série de Conferências Internacionais - ICED (International Conferences on Engineering Design) sobre métodos de Design em Engenharia. Paralelamente a esse movimento observa-se o crescente avanço nas pesquisas sobre teoria e metodologia do Design nos EUA - fins da década de 1980, não podendo deixar de mencionar: as publicações do Design Methods Group (Grupo de Métodos em Design), a série contínua de Congressos da Environmental Design Research Association (EDRA) - Associação de Pesquisa em Design do Ambiente e a iniciativa da The National Science Foundation (Fundação Nacional de Ciência) sobre teoria do Design e Métodos e ainda as ações da The American Society of Mechanical Engineers (ASME) - Associação Americana dos Engenheiros Mecânicos, que lançou uma série de conferências sobre teoria do Design e metodologia.

O que se viu na década de 1980 foi a consolidação da pesquisa no Design e o real estabelecimento do campo da teoria e metodologia dessa área. Neste conciso 
apontamento histórico, sobre a evolução dos métodos de pesquisa em Design, vale acrescentar a importância significativa dos primeiros periódicos científicos da área, como a Design Studies Research - DRS (Estudos e Pesquisa em Design) em 1979 e Design Issues (Investigação em Design) em 1984 e Research in Engineering Design (Pesquisa de Design em Engenharia) de 1989 - todas publicações de língua inglesa. Também é deste período o surgimento de livros com ênfase na cognição e projeto como do campo da arquitetura, How the Designers think? (LAWSON, 1980) e Design Thinking (ROWE, 1987). Observa-se que na década 1980, o Design emergiu como uma disciplina coerente de estudo em sua própria retidão, baseada na visão de que o projeto tem suas próprias peculiaridades a desenvolver e as suas próprias maneiras de conhecê-los.

As contínuas publicações que se sucederam na década de 1990, bem como o surgimento de novos periódicos: The Design Journal, The Journal of Design Research e CoDesign, e ainda os inúmeros congressos em várias regiões do planeta, culminaram no que podemos afirmar "maior idade do Design". A série de eventos internacionais contribuíram para a expansão para outras áreas diferentes da teoria e metodologia, bem como para o processo de consolidação da área, destaca-se aqui: Design Thinking, Doctoral Education in Design, Design Computing and Cognition, Design and Emotion, European Academy, the Asian Design Conferences, entre outros. A pesquisa em Design agora opera em uma escala verdadeiramente internacional.

\section{MÉTODOS DE DESIGN DIFUNDIDOS NO BRASIL NO FINAL DO SÉCULO. XX}

Conforme externado anteriormente, os estudos sobre metodologia de projeto em Design tiveram seu início entre as décadas de 50 e 60 e naturalmente evoluíram gradualmente frente às necessidades impostas pela sociedade, pelos sistemas econômicos, pela tecnologia e ainda por outras questões como o meio ambiente, mais recentemente. Considerando-se as diferentes demandas e os diversos cenários na qual as propostas metodológicas são desenvolvidas, nota-se elevado e diversificado número de métodos e metodologias de projeto para o Design elaborados longo do tempo. Sendo assim, selecionou-se para este estudo três métodos de Design utilizados nas últimas décadas do século $\mathrm{XX}$, desenhando uma breve trajetória cronológica sobre o assunto, a partir das publicações que tiveram maior impacto junto ao ensino de métodos de Design no Brasil. Não serão explicitadas as minucias de cada método, porém serão apontadas as características principais e seu "diferencial" na contribuição no processo de projeto, frente a realidade sócio econômica brasileira, considerando-se a época que cada metodologia foi publicada (ou traduzida) para o português. Os autores selecionados para representar os métodos de Design nas décadas de 70, 80 e 90 são: Lobach (1976), Bonsiepe (1984) e Baxter (1998), respectivamente.

A escolha destes autores, mestres do Design (mestres no sentido acadêmico da palavra - todos exerceram ou exercem a docência em Universidades em várias partes do mundo) se deu a priori por suas contribuições relevantes no campo do Design, principalmente no que diz respeito a desenvolvimento de métodos, e por suas propostas metodológicas refletirem o pensamento de uma época, frente a um cenário socioeconômico existente. Transitam com tranquilidade o universo acadêmico das Universidades e o mercado. Em comum, apresentam uma estreita aliança entre as 
atividades do Design desenvolvidos em seus cursos e laboratórios e o meio corporativo, seja através da coordenação ou implantação de instrumentos de promoção do Design, seja através de prestação de serviços em planejamento e desenvolvimento de produtos. Apresenta-se a seguir o Quadro 01 - Comparativo resumo do método de Design apontando: o autor, ano de publicação, a proposta metodológica e seu maior diferencial.

\begin{tabular}{|c|c|c|}
\hline \multicolumn{3}{|c|}{ QUADRO COMPARATIVO ENTRE MÉTODOS DE PROJETO EMPREGADOS NO DESIGN } \\
\hline Autor / Ano & PROPOSTA METODOLÓGICA & DIFERENCIAL \\
\hline $\begin{array}{l}\text { BERNRD } \\
\text { LOBÄCH } 1976\end{array}$ & $\begin{array}{l}\text { Caracterizado por ser um processo linear de etapas: } \\
\text { estruturalista, cartesiano e sistemático. Löbach (2009, } \\
\text { p. 142) propõe dividir o problema em } 4 \text { fases } \\
\text { distintas: } \\
\text { 1. Fase de preparação - Análise do problema: } \\
\text { conhecimento do problema; coleta de informações } \\
\text { análise das informações; definição do problema, } \\
\text { clarificação do problema; definição de objetivos. } \\
\text { 2. Fase da geração - Alternativas do problema: } \\
\text { escolha dos métodos de solucionar problemas, } \\
\text { produção de ideias, geração de alternativas } \\
\text { 3. Fase da avaliação - Avaliação das alternativas do } \\
\text { problema: exame das alternativas; processo de } \\
\text { seleção; processo de avaliação. } \\
\text { 4. Fase de realização - realização da solução do } \\
\text { problema; nova avaliação da solução. }\end{array}$ & $\begin{array}{l}\text { Destaca a lógica de } \\
\text { avanços e retrocessos } \\
\text { (loops) ao longo do } \\
\text { processo de design. } \\
\text { Embora caracterize-se } \\
\text { por um processo linear. } \\
\text { Estruturalista, cartesiano } \\
\text { e sistemático. Acredita } \\
\text { que a partir de análise } \\
\text { do problema eficiente, } \\
\text { fatalmente se chegará } \\
\text { ao encontro da solução } \\
\text { do problema. }\end{array}$ \\
\hline $\begin{array}{l}\text { GUI BONSIEPE } \\
1984\end{array}$ & $\begin{array}{l}\text { Defende a "taxonomia dos problemas", que seria uma } \\
\text { espécie de "classificação" dos problemas a serem } \\
\text { resolvidos. Os problemas de projeto seriam separados } \\
\text { em "problemas bem definidos" e "problemas mal } \\
\text { definidos", ou melhor "problemas estruturados" e } \\
\text { "problemas mal estruturados". } \\
\text { O processo projetual, faz parte de uma macro } \\
\text { estrutura que pode ser dividida em } 7 \text { (sete) passos: } \\
\text { 1. Problematização. } \\
\text { 2. Análise: análise sincrônica; análise diacrônica; } \\
\text { análise das características do uso do produto; análise } \\
\text { funcional; análise estrutural; análise morfológica. } \\
\text { 3. Definição do problema: estruturação do } \\
\text { problema; fraccionamento e hierarquização; } \\
\text { 4. Anteprojeto - geração de alternativas: } \\
\text { brainstorming; método 635; cinética-busca de } \\
\text { analogias, métodos de transformação; criação } \\
\text { sistemática de variantes; "caixa" morfológica; } \\
\text { desenhos, esboços; maquete, pré-modelo, modelo. } \\
\text { 5. Avaliação, decisão, escolha: etapa que faz-se } \\
\text { necessário analisar as alternativas propostas e avaliá- } \\
\text { las de acordo com a lista de critérios levantados na } \\
\text { fase de problematização, análise e definição do } \\
\text { problema. } \\
\text { 6. Realização: esta etapa seria destinada as decisões } \\
\text { finais, ou seja com a participação da diretoria, } \\
\text { marketing, engenharia de produção. } \\
\text { 7. Análise final da solução. } \\
\text { O autor propõe pelo menos quatro tipos diferentes } \\
\text { sequenciais dos sete passos propostos no processo }\end{array}$ & $\begin{array}{l}\text { Aponta que a } \\
\text { metodologia apenas } \\
\text { auxilia o designer no } \\
\text { processo projetual, } \\
\text { destacando técnicas e } \\
\text { métodos específicos em } \\
\text { cada etapa do projeto. } \\
\text { Sugere uma série de } \\
\text { análises sobre o objeto } \\
\text { em estudo para melhor } \\
\text { compreensão do } \\
\text { problema. } \\
\text { O autor propõe um } \\
\text { relativização entre o } \\
\text { método proposto e o } \\
\text { nível de complexidade } \\
\text { do problema que o } \\
\text { designer enfrentará. } \\
\text { O autor trabalha com a } \\
\text { ideia de que não há } \\
\text { apenas uma sequência } \\
\text { linear de etapas. }\end{array}$ \\
\hline
\end{tabular}




\begin{tabular}{|c|c|c|}
\hline & $\begin{array}{l}\text { projetual, podendo ser: tipo } 1 \text { - linear, tipo } 2 \text { - com } \\
\text { feed-back, tipo } 3 \text { - circular e o tipo } 4 \text {. Desta forma o } \\
\text { autor sugere que haja uma "adequação" do modelo } \\
\text { mais conveniente (de acordo com a complexidade do } \\
\text { problema) ao processo de projeto. }\end{array}$ & \\
\hline $\begin{array}{l}\text { MIKE BAXTER } \\
1998\end{array}$ & $\begin{array}{l}\text { Abrange de forma integral o processo de } \\
\text { desenvolvimento de novos produtos, partindo da } \\
\text { pesquisa de mercado, passando pelo projeto } \\
\text { conceitual, desenvolvimento e especificações até a } \\
\text { fabricação. Gerenciamento das atividades de projeto: } \\
\text { 1. Ideias preliminares: “Nessa etapa, o produto pode } \\
\text { ser apresentado na forma de um simples desenho de } \\
\text { apresentação, para ser mostrado a um pequeno } \\
\text { número de potenciais consumidores ou vendedores". } \\
\text { Caso aprovado, passa-se para a etapa seguinte. } \\
\text { 2. Especificações: especificação da oportunidade e } \\
\text { do projeto; parte-se então para o projeto conceitual, } \\
\text { a fim de selecionar o melhor conceito. } \\
\text { 3. Configurações: O conceito selecionado é } \\
\text { submetido a um segundo teste de mercado, iniciando } \\
\text { a terceira etapa. Caso esse novo teste for satisfatório, } \\
\text { deverão ser iniciadas as atividades de configuração do } \\
\text { produto. Poderá haver retrocesso de uma ou duas } \\
\text { etapas. } \\
\text { 4. Produção: sendo aprovado passa-se para os } \\
\text { desenhos detalhados do produto e seus } \\
\text { componentes, desenhos para fabricação e a } \\
\text { construção do protótipo. A aprovação "oficial” desse } \\
\text { protótipo encerra o processo de desenvolvimento do } \\
\text { produto. } \\
\text { O autor considera essa atividade como um } \\
\text { problema de difícil solução e multifatorial. Sugere: } \\
\text { resolva o problema por etapas e siga as } \\
\text { especificações: exigências que o produto deve possuir } \\
\text { ou desejos para ser comercialmente atrativo. Deve } \\
\text { haver aprovação em todos departamentos da fábrica. }\end{array}$ & $\begin{array}{l}\text { Articula design e } \\
\text { marketing e produção } \\
\text { (inovação) a fim de } \\
\text { alcançar diferenciação no } \\
\text { mercado. } \\
\text { Defende que o sucesso de } \\
\text { um produto dependerá: } \\
\text { da oportunidade de } \\
\text { negócio e orientação para } \\
\text { o mercado, além da } \\
\text { participação e ação } \\
\text { conjunta com todos os } \\
\text { setores da empresa. } \\
\text { Não apresenta um método } \\
\text { a ser adotado como } \\
\text { caminho único para o } \\
\text { desenvolvimento de novos } \\
\text { produtos. O autor } \\
\text { apresenta uma estrutura } \\
\text { gerencial de projeto. } \\
\text { Dentro dessa estrutura, } \\
\text { foram elaborados alguns } \\
\text { quadros denominados } \\
\text { ferramentas toolkit de } \\
\text { projeto, para condensar as } \\
\text { principais etapas do } \\
\text { processo de } \\
\text { desenvolvimento de novos } \\
\text { produtos }\end{array}$ \\
\hline
\end{tabular}

Quadro № 01 - Comparativo de métodos de projeto em Design, empregados no final séc. XX. Fonte: Elaborado pelo autor, com base na pesquisa realizada

\section{1 - Considerações sobre o método de Bernard Löbach (1976)}

Apesar da formação em Design e Sociologia, Löbach deixa claro através de sua metodologia o caráter cartesiano, estruturalista e racionalista desenvolvido em seu processo de Design. Certamente isso ocorreu principalmente devido a influência dos estudos sobre metodologia, produzidos anteriormente por parte de engenheiros, que "entendiam" o processo de design como uma sequência linear de etapas. Também não podemos desconsiderar a origem natural alemã do autor, bem como as influências do cenário econômico, social e político da época. Bernard Löbach atuou durante anos no curso de Design da Fachhochschule de Bielefeld, Alemanha, onde fez diversas publicações importantes. Atualmente é docente da Hochschule fur Bildende Kunste. A publicação original do livro Industrial Design, Grundlagen der 
Industrieproduktgestaltung (Design Industrial, bases para a configuração dos produtos industriais), teve sua primeira edição em 1976 em alemão, e depois em 1981 em espanhol - muito importante para a formação de muitos dos nossos designers.

O autor propõe a setorização por etapas do processo de Design, deixando claro a forte influência dos metodólogos da década de 1960, com inclinação para as engenharias onde sinaliza-se seu entendimento sobre metodologia como ciência. Desta forma a visão do autor faz eco à forma de compreender a base metodológica desenvolvida para a metodologia: "Da fusão entre o método indutivo do empirismo e o método dedutivo do racionalismo constituiu-se a base metodológica fundamental da ciência moderna" (CIPINIUK \& PORTINARI, in COELHO (org.) 2006, p. 18)

Löbach (2009) defende com razão uma preocupação mais cuidadosa na primeira fase do seu método, com o estudo mais elaborado do problema, ou seja, a demanda do projeto. O autor subdivide essa primeira etapa em três importantes etapas: conhecimento do problema, coleta e análise de informações. A par das informações "julgadas necessárias", Löbach (2009) aponta cerca de dez tipos diferentes de análises na fase processo de design. A princípio nos parece uma análise bastante aprofundada para o planejamento de um novo projeto de design, o que fatalmente traria segurança para o desenvolvimento das etapas seguintes.

A fase seguinte geração de alternativas, prossegue (segundo o autor) como resultado quase que natural após realizadas as análises da fase análise de problema. Nos chama atenção para forma linear e quase "receituária" de como chegar-se a uma solução para o problema: "Para elaborar soluções para os problemas são possíveis dois tipos distintos de procedimentos, que também podem se apresentar de forma mista: (1) tentativa e erro, (2) aguardar inspiração".

A ideia de Löbach (2009) sobre a geração de alternativas, através de tentativa e erro, a partir das análises do problema em estudo, reforça a ideia que quanto mais inserido nas questões do problema de design, mais chance o designer dispões de propor melhores soluções. Contudo, Lawson (2011), faz uma interessante afirmação sobre a relação problemas de design e solução: "Como os problemas de projeto escapam a descrições completas e permitem um número inesgotável de soluções, o processo de projeto não pode ter um fim determinado e identificável". Nesse sentido, fica claro que a sequência lógica, problemas, alternativas e soluções - nessa ordem, pode muita vezes não funcionar (Lawson, 2011 p. 120). Entendendo-se a proposta de Löbach (2009) como um processo de Design linear, o autor afirma que as avaliações devem considerar as análises de problema realizadas, onde serão estabelecidos critérios para a escolha da melhor alternativa.

A última etapa da metodologia de Löbach (2009) é a fase 4: Realização da solução do problema. Nesta fase pressupõe-se que as questões detectadas na fase de análise do problemas tenham sido equacionadas e que a alternativa proposta atenda de melhor forma possível as soluções requisitadas. Observa-se que o método descrito aqui, trata esta fase como o encerramento, ou a conclusão lógica de uma sequência de passos. Esta visão mecanicista que muito marcou a primeira geração de metodólogos 
na década de sessenta, ainda alimentava as ideias das metodologias para processos de Design na década de 70.

Apesar de seu caráter racional e linear, este método foi muito importante para muitas gerações de designers, que utilizaram-se dos ensinamentos de Löbach (2009) para soluções de seus próprios problemas de Design. Naturalmente que cada um fez seus ajustes e adaptações que julgou necessário implementar. No Brasil havia uma carência de textos básicos sobre design industrial e metodologia de projeto, os quais muitos designers brasileiros inspiraram-se na versão em espanhol de 1981, para implantar seu próprio modus faciendi, no processo de elaboração de projeto em design. Na época vivia-se a fase do "milagre econômico" em meio a ditadura militar que caminhava vagarosamente para seu declínio. A indústria brasileira tenta modernizar-se no meio a uma crise no mundial do petróleo (OPEP - Organização dos países exportadores de petróleo). Mesmo o Brasil sendo muito mais importador de tecnologia, bem como de produtos manufaturados, alguns setores da economia apontavam o investimento em Design como uma das alternativas viáveis para o fortalecimento da indústria brasileira. Esse idealismo socioeconômico, fortalecido principalmente pelo crescente número de cursos na área do Design, seria cada vez mais perseguido nas décadas seguintes.

\section{2 - Considerações sobre o método de Gui Bonsiepe (1984)}

A metodologia proposta por Bonsiepe (1984), afasta-se do perfil absolutista, que desde a década de 60 permeava a grande maioria do métodos em Design. $O$ autor propõe um relativização entre o método proposto e o nível de complexidade do problema que o designer enfrentará. Parte de uma estrutura principal que deverá ir adequando-se de acordo com a complexidade do problema em questão. Nesse sentido, projetos de menor complexidade poderiam seguir um processo mais linear, sem a necessidade excessiva de verificação das alternativas versus definição problema. Em outros casos (com maior complexidade) haveria ênfase ao feed-back, e checagem constante, entre cada fase do processo.

Percebe-se sensível adequação do método de Bonsiepe (1984), às questões específicas do processo metodológico em Design, diferenciando-se dos modelos adotados nas décadas de sessenta e setenta, quando havia uma aproximação entre as metodologias propostas e os modelos com origem na engenharia. Nesse sentido, aspectos como problematização, geração de alternativas e definição de problemas são tratados como questões inerentes ao desenvolvimento de produto, acentuando a atenção do designer para estas condicionantes.

A proposta metodológica pensada por Bonsiepe (1984), que estudou Design na HFG UIm - Hochschule für Gestaltung, Ulm, (1955-1959), chega ao Brasil, num período de grandes mudanças políticas, econômicas e sociais. A década de 80 no Brasil é marcada pelo fim da ditadura militar com a abertura política e eleições diretas - após movimentos populares de várias camadas da sociedade, que realizaram grandes pressões por eleições e mais tarde culminou no movimento nacional "Diretas Já". O cenário econômico não era dos melhores. Havia altos índices inflacionários e longo período de estagnação econômica. Por conta deste contexto econômico conturbado, 
houve tentativas de reforma monetárias e vários planos econômicos foram adotados. Infelizmente todos fracassaram ou seus resultados foram insuficientes para manter a estabilidade econômica que chegaria apenas na década de 90 . Assim, a década de 80 ficou conhecida como a década perdida (do ponto de vista econômico, do crescimento e do desenvolvimento) que culminaria com uma hiperinflação.

A atuação de Gui Bonsiepe, no Brasil, ajudou a difundir a prática de metodologia de projeto - principalmente através de sua atuação no Laboratório Brasileiro de Desenho Industrial - LBDI - Santa Catarina, Florianópolis (1984 - 1987), considerando que as publicações estrangeiras eram escassas e a publicações nacionais, quase inexistentes. O livro Metodologia Experimental: Desenho Industrial (1984), coordenado por Bonsiepe, com colaboração de Petra Kellner e Holger Poessnecker (utilizado neste estudo), foi publicado no Brasil, através das iniciativas do CNPQ, como registro das principais conclusões do II Curso de Atualização em Projeto de Produto/Desenho Industrial, realizado na Universidade Federal da Paraíba - UFPB, em Campina Grande.

Esta metodologia foi amplamente difundida nas escolas de Design de nível universitário. Nesse período da década de 1980 os cursos de Desenho Industrial (como se chamava na época, e não Design) se multiplicaram. Muitos cursos e laboratórios de pesquisas faziam parte de um plano maior do estado preocupado com 0 desenvolvimento do design industrial.

\section{3 - Considerações sobre o método de Mike Baxter (1998)}

Baxter (1998) propõe uma metodologia que procura integrar aspectos sobre a criação e projeto de novos produtos, junto com ações do ponto de vista do mercado e da engenharia. $O$ autor entende que a descoberta das necessidades de mercado e a concepção e desenvolvimento de produtos, para satisfazer a essas necessidades, são consideradas como partes do mesmo processo. Sendo assim o método de Baxter (1998) pretende abranger de forma integral o processo de desenvolvimento de novos produtos, partindo da pesquisa de mercado, passando pelo projeto conceitual, desenvolvimento e especificações até a fabricação.

Entre os métodos estudados nesta breve análise sobre metodologia do Design industrial utilizadas no final do século XX, o método proposto por Baxter (1998) é o mais abrangente. Diferenciando-se dos demais métodos que tratam do assunto apenas do ponto de vista da engenharia ou do mercado, Baxter integra os dois aspectos. Para o Design o termo mercado de forma recorrente é aplicado como sinônimo do espaço onde se dá a "prática do design", conforme explica Damásio (2008) "é comumente entendido como principal destino dos produtos do design, e ponto de encontro com as pessoas para os quais foram projetados (DAMÁSIO, 2008 in, COÊLHO (org.) 2008, p.74).

Baxter (1998) destaca entre as atividades de projeto, nas diferentes etapas do desenvolvimento de produto a preocupação do mercado como demanda. Desta forma, o autor monta seu esquema de "criação" de novos produtos a partir da análise da oportunidade de negócio, que o autor considera fundamental a preocupação do 
designer para a orientação para o mercado - "o produto precisa apresentar forte diferenciação em relação aos seus concorrentes no mercado". Considerando este aspecto do método proposto, pode-se afirmar que a geração de novos produtos está diretamente ligada a necessidade do consumidor (nem que esta tenha que ser "criada").

Outro aspecto interessante sobre as ideias de Baxter (1998) é que o autor considera como atividade de projeto, para o desenvolvimento de um novo produto o teste das necessidades de mercado, na fase inicial e teste de mercado antes da aprovação final do protótipo de produção industrial, na fase final. Estas ações incrementadas no esquema de desenvolvimento de novos produtos, reafirmam a preocupação do autor com as questões ligadas a viabilidade econômica e atendimento a uma necessidade detectada para um futuro público consumidor.

Outras questões também são consideradas no método proposto por Baxter (1998) como um avanço no entendimento sobre métodos de desenvolvimento de projeto como, estudo das viabilidades técnicas e de produção, testes de materiais, viabilidade econômica - no que tange investimentos necessários e a cooperação entre os principais setores da empresa, como diretoria, engenharia e marketing recomendações feitas pelo autor. Esta visão global traduz uma metodologia de projeto orientada para as necessidades do consumidor e do mercado.

Considerando-se que o autor atualmente é professor do curso de Design da Universidade de Brunel, Londres (Inglaterra) e diretor do Design Centre Research Brunel University (Londres) onde dirige uma equipe de designers e engenheiros, que prestam serviços às empresas, sinalizando proximidade com o meio produtivo, percebe-se a estreita ligação do autor com o mercado. Diante de um cenário mundial de globalização de grandes empresas e trocas de informação nunca experimentadas, a proposta de Baxter (1998) traz para o método de projeto em design, discussões que antes não eram tratadas, ou que simplesmente eram negligenciadas. Seguramente o grande mérito do método, neste cenário industrial cada vez mais competitivo, é conseguir tratar com o mesmo nível de importância as questões técnicas da engenharia e as questões das necessidades dos consumidores identificadas nas pesquisas de mercado.

As ideias de Baxter (1998) começam a ser aplicadas no final da década de 1990 e início do novo milênio nos curso de graduação em Design Industrial no Brasil, logo depois da publicação da versão em português do seu título em 1998. O final de milênio retrata o país em um novo momento de sua realidade econômica e social. Durante a década de 90 o Brasil passou por mudanças significativas, principalmente nas questões ligadas à política de comércio exterior. O período caracterizou por um processo de abertura comercial abrangente e progressivo, que se iniciou no governo do presidente Fernando Collor (1992) e se estendeu até o governo Fernando Henrique Cardoso (1998). A abertura comercial caracterizou-se principalmente pela integração entre países e acordos bilaterais, bem como diminuição das barreiras protecionistas da indústria brasileira, nos moldes da nova ordem mundial de globalização. Em 1994, na gestão do então presidente Itamar Franco, foi criado o Plano Real - este que seria o mais bem sucedido plano econômico, retirando o país de um cenário recorrente de 
hiperinflação e baixos investimentos na indústria. Começa a ser desenhado um cenário de boas expectativas para a indústria brasileira, que precisava se tornar competitiva e enfrentar a concorrência dos produtos importados.

\section{CONSIDERAÇÕES FINAIS}

A compreensão da situação sócio econômica de um país através do design, passa pelo entendimento do seu processo de industrialização, o qual não é um movimento autônomo, mas dependente da política econômica da nação. Apesar do Brasil caracterizar-se por ser exportador de produtos agrícolas (dependente do mercado mundial) as tentativas de investimento em Design, através de políticas públicas vem ocorrendo com uma certa regularidade, através de alguns programas governamentais de desenvolvimento com incremento do fator design. Sabe-se que o investimento em Design no Brasil ao longo dos anos, passou por diversas fases, das quais podemos destacar a ampliação da oferta de cursos de graduação, o surgimento dos curso de pós-graduação e programas específicos que promovem o design como ferramenta de incremento para a produção de produtos de qualidade. Infelizmente ainda observa-se escassos investimentos em pesquisa, desenvolvimento e tecnologia nos centros geradores de conhecimento a fim de contribuir de forma decisiva com o desenvolvimento do país.

Observa-se que a literatura utilizada para os estudos de métodos de projeto em design (assim como ocorre em outras áreas do conhecimento), chegam às universidades com significativa defasagem temporal (o título de Löbach, foi lançado originalmente em 1976, na Alemanha e sua versão em português, foi publicada somente em 2001 no Brasil). Considerando-se a dinâmica dos processos de produção e a busca incessante em satisfazer as necessidades dos usuários, entende-se que a carência de publicações locais que contribuam na solução de questões nacionais, com suas devidas peculiaridades ainda é uma lacuna a ser preenchida.

\section{AGRADECIMENTOS}

Pontifícia Universidade Católica do Rio de Janeiro - PUC - Rio.

Fundação de Amparo à Pesquisa e Desenvolvimento Científico do Maranhão.

\section{REFERÊNCIAS}

BAXTER, Mike. Projeto de produto: guia pratico para o design de novos produtos. Tradução Itiro lida, 1998. 3 ed. São Paulo: Blucher, 2012. Titulo original: Product design: a pratical guide to systematic methods of new product development.

BONSIEPE, Gui. Et al. Metodologia experimental: desenho industrial. Brasília, CNPQ/Coordenação editorial, 1984. 86p.

CIPINIUK, Alberto \& PORTINARI, Denise. Sobre métodos de Design. In: COELHO, Luiz Antônio (org.). Design Método. Rio de Janeiro: PUC Rio e Novas ideias, 2006

COELHO, L. A. (org.) Design Método. Rio de Janeiro: PUC Rio e Novas ideias, 2006

COELHO, L. A. (org.). Conceitos-chave em design. Rio de Janeiro: PUC-Rio, 2008

CROSS, Nigel, Developments in design methodology. London: John Wiley \& Sons, 1984

CROSS, Nigel. Forty years of design research. Design Research Quartely. New York: 2006,

Design Research Society. v 1, 35 p (www.designresearchsociety.org) 
DARKE, Jane. The primary generator and the design process. In: CROSS, Nigel (org.) Developments in Design Methodology, Cross (org.) London: John Wiley \& Sons, 1984

LAWSON, B. Como arquitetos e designers pensam. Tradução Maria Beatriz Medina.2 ed. São Paulo: Oficina de textos. 2011. Titulo original: How designers think: the design process demystified.

LÖBACH, B. Design industrial. Bases para a configuração dos produtos industriais. Tradução Freddy Van Camp. São Paulo: Blucher, 2001, 2a reimp. 2009. Título original: Industrial Design. Grundlagen der Industrieproduktgestaltung

ROOZENBURG, N. F. M e EEKELS, J. Product Design: Fundamentals and methods. West Sussex, UK: John Wiley \& Sons, 1995 